\title{
The Correlation between Malondialdehyde Level with Vitiligo
}

\section{Severity}

\author{
Widayati R, Budiastuti A, Yogyartono P and Riyanto P* \\ Department of Dermatology and Venereology, Diponegoro University/Kariadi \\ Hospital, Indonesia
}

*Corresponding author: Dr. Puguh Riyanto, MD, DV, Department of Dermatology and Venereology, Faculty of Medicine, Diponegoro University/Kariadi Hospital;

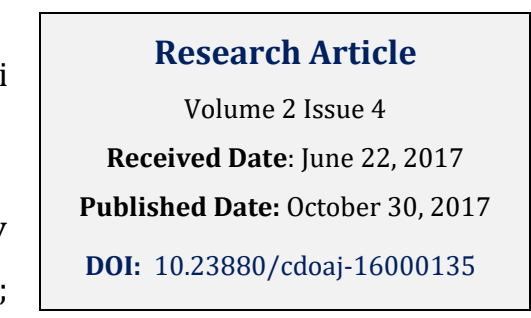
Semarang, Indonesia. Dr. Soetomo street 18 Semarang city, central java, Indonesia, Tel: 0816650792; E-mail: Puguhungaran@gmail.com

\section{Abstract}

Background: Vitiligo is an idiopathic disorder characterized by macular hypopigmentation due to melanocyte impairment and the absence of melanin production. There is an antioxidant-prooxidant ratio shift involved in oxidative stress. Malondialdehyde (MDA) is a stable product of lipid peroxidation and is a biologic marker of the increased oxidative stress. VASI is a parametric quantitative score that is sensitive to evaluate the degree of vitiligo severity.

Objective: To determine the correlation between oxidative stress with vitiligo severity

Methods: An analytical observational cross sectional study with consecutive sampling design

Result and Conclusion: There is a positive and significant correlation ( $p=0.001 ; r=0.94)$ between MDA plasma level and the degree of vitiligo severity based on Vitiligo Area Severity Index (VASI).

Keywords: Vitiligo; VASI; Malondialdehyde

Abbreviations: VASI: Vitiligo Area Severity Index; MDA: Malondialdehyde.

\section{Introduction}

Vitiligo is a skin disorder characterized by macular hypopigmentation, distributed symmetrically in the human body. Vitiligo is caused by the destruction of the skin melanocytes, mucous membranes, eyes, inside of the ear, leptomeningeal, and hair bulb. Generally, melanocytes are not found in vitiligo lesions, but sometimes the inactive melanocytes may be found in the vitiligo lesion. Vitiligo can cause cosmetic problems that may affect psychological and social conditions not only for the patients and but also their families [1,2].

The etiology of vitiligo is not yet clear, however some studies stated that it is caused by genetic factors and some other precipitating factors; i.e. physical trauma, emotional stress, severe systemic diseases, oxidative stress, and free radical accumulation. The imbalance between the oxidant and the antioxidant could trigger the oxidative stress that results in cell damages. Oxidative stress is one of the pathological mechanisms in vitiligo, also a probable trigger factor in melanocyte degeneration which may be presented as $\mathrm{H} 2 \mathrm{O} 2$ accumulation in vitiligo patients $[2,3]$. 


\section{Clinical Dermatology Open Access Journal}

Malondialdehyde (MDA) is the end-product of stable lipid peroxidation and it is commonly used as biologic marker of the increasing of oxidative stress level. The increasing level of MDA plasma is reported in active vitiligo patients. The increased levels of MDA can be observed in plasma, serum, urine, and tissue samples measured by spectrophotometry.

The objective of this study is to determine the association between oxidative stress with the degree of vitiligo severity by measuring MDA plasma level in vitiligo patients.

\section{Method}

This was an analytical observational cross sectional study. The study population was vitiligo patient who visited the dermatology and venereology clinic at Dr. Kariadi Hospital, Semarang, Indonesia during the study period. The inclusion criterias were patients with vulgaris, segmental, or acrofacial vitiligo who were at least 14 years old, Indonesian citizen and could provide inform consent to participate in the study. Vitiligo patients were excluded from the study if they smoke, had antioxidant consumption history, suffered from any inflammatory skin disease and or skin burns, a chronic systemic disease and acute infection.

The sample selection was done by consecutive sampling based on patients' visit to the Dr. Kariadi hospital, Semarang. The sample size was calculated by the sample formula for the correlation test. The possibility of drop out due to blood sample damage was estimated at a maximum of $10 \%$, so that 33vitiligo patients were needed as the study population, and the numbers were derived from the calculation of the large formula of samples for correlation test.

The degree of vitiligo severity was evaluated in the study subjects, and $6 \mathrm{ml}$ blood sample were drawn from the subjects into the vacutainer tube and MDA plasma level were examined. Normality of data distribution was analyzed by Saphiro Wilk test. The data was considered normal if the $\mathrm{p}$ value $>0,05$.

Categorical data such as gender and the degree of vitiligo severity were presented as distribution or percentages. Pearson parametric test was used to analyze the association between MDA plasma level and the degree of vitiligo severity if the data was in accordance with the normal distribution. If the data did not correspond to the normal distribution, the association would be analyzed by the Rank Spearman non-parametric correlation test. Positive or negative correlation was presented by the correlation direction and coefficient correlation is presented as the correlation degree.

Ethical clearance was given by Health Research Ethical Committee, Faculty of Medicine, Diponegoro University, dr Kariadi Hospital, Semarang.

\section{Results}

Most participants were males (66.7\%) and aged 14-66 years old (mean $37.79+15,81$ years old). The majority ofpatients did not have vitiligo history in the family $(81.8 \%)$, did not have a habit of high intensity sport (78.8\%). A large number of patients reported frequent sun exposure (54.4\%) (Table 1).

\begin{tabular}{|c|c|c|}
\hline Characteristics & $\begin{array}{c}\text { Rerata + SB; } \\
\text { Median (min-max) } \\
\end{array}$ & N (\%) \\
\hline \multirow{2}{*}{ Age } & $37,8+15,81$ & \\
\hline & $35(14-66)$ & \\
\hline \multicolumn{3}{|c|}{ Gender } \\
\hline Men & & $22(66,7)$ \\
\hline Female & & $11(33,3)$ \\
\hline \multicolumn{3}{|c|}{ Vitiligo history } \\
\hline Yes & & $6(18,2)$ \\
\hline No & & $27(81,8)$ \\
\hline \multicolumn{3}{|c|}{ Habit of high intensity sports } \\
\hline Yes & & $7(21,2)$ \\
\hline No & & $26(78,8)$ \\
\hline \multicolumn{3}{|c|}{ Sun exposure } \\
\hline Yes & & $718(54,5)$ \\
\hline No & & $15(45,5)$ \\
\hline
\end{tabular}

Table 1: Characteristics of study population. 
Three independent observers separately evaluated the frequency distribution of the degree of vitiligo disease employing VASI score in the same day. The measurement was done by three independent observers due to high subjectivity. The reliability of VASI results among observers was assessed using the Kappa suitability test, and a suitability score $>70 \%$ was obtained. The VASI assessment resultedin 11 patients with mild vitiligo (33.3\%), 11 patients with moderate vitiligo (33.3\%) and 11 patients with severe vitiligo (33.3\%) (Figure 1).

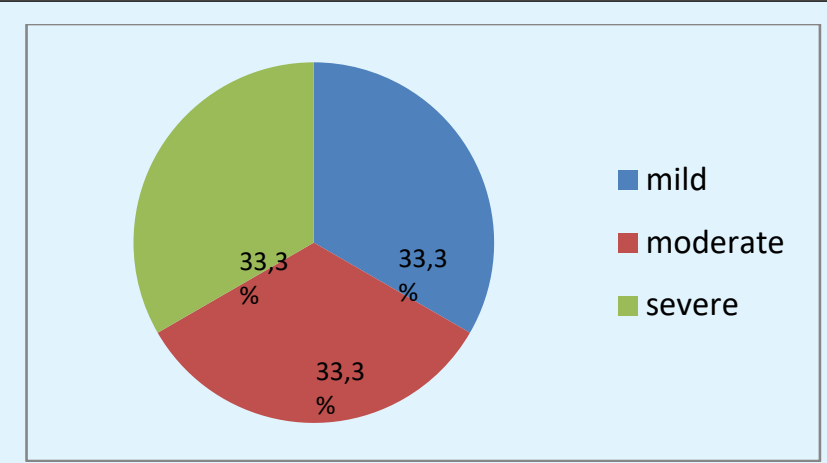

Figure 1: The Distribution of the Vitiligo Severity Degree in Study Population $(n=33)$.

There was no association between the degree of vitiligo severity with gender ( $p>0.05)$ from the statistical test, no significant association between degree of vitiligo severity with habit of high intensity sport ( $\mathrm{p}>0.05)$, and no significant association with sun exposure history ( $\mathrm{p}<$ 0.05).

The result of MDA plasma measurements ranged between $39.77 \mathrm{ng} / \mathrm{ml}$ to $1464.20 \mathrm{ng} / \mathrm{ml}$ (mean + standard deviation $=225.86+274.21)($ Table 2$)$.

\begin{tabular}{|c|c|c|c|c|}
\hline \multirow{2}{*}{$\begin{array}{c}\text { Study } \\
\text { participants }\end{array}$} & \multicolumn{4}{|c|}{ MDA plasma level } \\
\cline { 2 - 5 } & Mean + SD & Median & Minimum & Maximum \\
\hline Mild & $\begin{array}{c}72,59+ \\
18,26\end{array}$ & 71,51 & 39,77 & 99,25 \\
\hline Moderate & $\begin{array}{c}132,32+ \\
16,57\end{array}$ & 131,20 & 107,79 & 158,87 \\
\hline Severe & $\begin{array}{c}472,68+ \\
370,84\end{array}$ & 351,53 & 167,19 & 1464,20 \\
\hline Total (n=33) & $\begin{array}{c}225,86+274, \\
21\end{array}$ & 131,20 & 39,77 & 1464,20 \\
\hline
\end{tabular}

Table 2: MDA plasma level mean differences based on vitiligo severity degree.
As shown in the table 2 above, the lowest MDA plasma level found in patients with mild vitiligo $(72,59+18,26$ $\mathrm{ng} / \mathrm{ml}$ ), followed by moderate vitiligo patients with MDA plasma level of $132,32+16,57 \mathrm{ng} / \mathrm{ml}$ and the highest MDA plasma level was found in severe vitiligo patients $(472,68+370,84 \mathrm{ng} / \mathrm{ml})$.

The progresiveness of the vitiligo severity degree positively associated with the increase of MDA plasma level. Spearman test resulted in positive correlation with highly significant degree between MDA plasma level with vitiligo severity degree.

\section{Discussion}

Vitiligo is acquired depigmented skin disorder that affects $1-2 \%$ of global population [4-6]. Study participants consisted of vulgaris, segmental, or acrofacial vitiligo patients. The degree of vitiligo severity was assessed by using Vitiligo Area Severity Index (VASI) score. VASI is a quantitative parametric score that is sensitive to measure disease severity and vitiligo treatment evaluation, and it was first introduced by Hamzavietc. In 2004 [7,8]. Based on the VASI criteria, there were 11 mild (33.3\%), 11 moderate $(33,3 \%)$, and 11 severe vitiligo patients in this study.

The MDA plasma level ranged between $39.77 \mathrm{ng} / \mathrm{ml}$ to $1464.20 \mathrm{ng} / \mathrm{ml}$ (mean + standard deviation= $225.86+$ 274.21) in this study. This study has succeeded in proving that there is free radical and oxidative stress role in vitiligo pathogenesis. Moreover this study also found an association between oxidative stress due to free radical accumulation and reactive oxygen species (ROS) with the development of vitiligo-related components in blood and epidermis [9].

In this study, we found that the mean of MDA plasma level in patients with mild vitiligo was $72.59 \mathrm{ng} / \mathrm{ml}$, $132.32 \mathrm{ng} / \mathrm{ml}$ for moderate vitiligo patients, and 472.68 $\mathrm{ng} / \mathrm{ml}$ for severe vitiligo patients. From the results, we concluded that the increasing level of MDA plasma positively associated with the progressiveness of vitiligo severity degree. We suspected that the increasing MDA plasma level is one of the indicators of oxidative stress. MDA in the blood represents the lipid peroxidation and it is triggered by oxygen species as the indicator of oxidative stress.A destructive or a defective antioxidant defense leads to the increasing action of cytotoxic ROS which may start lipid peroxidation chain reaction producing lipid peroxides and lipoxides. The lipid peroxides and lipoxides decomposition produces many varieties of end-products which includes MDA. MDA is cytotoxic towards 


\section{Clinical Dermatology Open Access Journal}

melanocytes and can inhibit tyrosinase enzyme whichis suspected to have a role in vitiligo pathogenesis [10]. We concluded that there was positive correlation between MDA plasma level with the degree of vitiligo severity in this study due to oxidative stress loop circle (Figure 2).

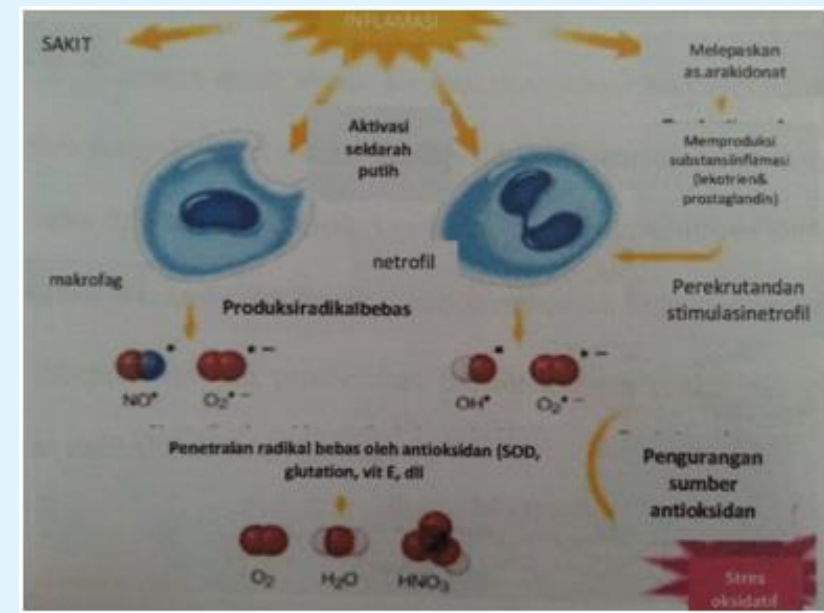

Figure 2: Oxidative Stress.

The result of this study suits the prior studies that oxidative stress holds an important role in vitiligo pathogenesis and has a destructive effect to melanocyte in vitiligo. This study also found that oxidative stress indicator such as MDA can be used as biomarker in evaluating the degree of vitiligo severity.

\section{Conclusion}

There is a positive and significant correlation between MDA plasma level and the degree of vitiligo severity based on Vitiligo Area Severity Index (VASI).

\section{References}

1. Chodorowska G, Bartosinska J, Dabrowska-Czlonka M, Wawrzycki B, Wojnowska D (2007) Involvement of Immunological Factors in The Pathogenesis of Vitiligo. Annales Universitatis Mariae CurieSklodowska 62: 182-187.
2. Abdel-Fattah NSA, Shaheen MA, Ebrahim AA, Okda El (2008) Tissue and Blood Superoxide dismutase activities and malondialdehyde levels in different clinical severities of acne vulgaris. Br J Dermatol 159(5): 1086-1091

3. Ortone JP (2003) Vitiligo and Other Disorders of Hypopigmentation. In: Bolognia JL, Jorizzo JL, Rapini RP. Dermatology. Torontoo: Mosby, pp: 947-970.

4. Conrad M, Wiliam C, Shier Jr Vitiligo: A Common Cause of Loss of Skin Pigment.

5. Taieb A, Picardo M (2009) Vitiligo: New England Journal Medicine 360: 160-9.

6. Halder RM, Taliaferro SJ (2008) Vitiligo. In: Wolff K, Goldsmith LA, et al. (Eds.), Fitzpatrick's Dermatology in General Medicine. $7^{\text {th }}$ (Edn.), McGraw-Hill Co., New York, pp: 616-622.

7. Nicolaidou E, Antoniou C, Stratigos A, Katsambas AD (2009) Narrowband Ultraviolet B Phototherapy and 308-nm Eximer Laser in the Treatment of Vitiligo: A Review. J Am Acad Dermatol 60(3): 470-477.

8. Kawakmi T, Hashimoto T (2011) Disease Severity Indexes and Treatment Evaluation Criteria in Vitiligo. Dermatol Res Prac 503-542.

9. Ozturk IC, Batcioglu K, Karatas F, Hazneci E, Genc M (2008) Comparison of plasma malondialdehyde, Glutathione, Glutathione peroxidase, Hidroxyproline and Selenium Levels in Patients with Vitiligo and Healthy Controls. Indian J Dermatol 53(3): 106-110.

10. El-Rafaei AM, Sorour NE, El-Shaer OS, Saied WS (2014) Oxidative Stress in The Blood of Patients with Active Localized Vitiligo. Med J Cairo Univ 82(2): 103107. 